\title{
Divorce Rate in the U.S.: Geographic Variation, 2019
}

\author{
Author: Leslie Reynolds
}

This Family Profile, an update to previous profiles on the divorce rate [FP-17-24; FP-18-21; FP-19-23], depicts adjusted divorce rates for the nation and each state for 2019. Using American Community Survey data, we estimate the number of divorces occurring in the last year among married women, calculate their margins of error, and describe geographic variation in the divorce rate. For detailed information on the adjusted divorce rate from 2008-2017, see "Charting Marriage \& Divorce in the U.S.: The Adjusted Divorce Rate" (Payne, 2018).

\section{U.S. Divorce Rate, $2019^{1}$}

- The divorce rate continued to decline in 2019, reaching a 40 -year low.

- The divorce rate was 15.5 divorces per 1,000 married women in 2019, down from a divorce rate of 15.7 in 2018 (FP-19-23).

- Just over one million women $(1,042,174)$ divorced in 2019.

${ }^{1}$ The divorce rate $=[$ (number of women divorced in the past 12 months) $/$ (number of women divorced in the past 12 months + number of currently married women)]*1000

Figure 1. Women's Adjusted Divorce Rate, 1970-2019

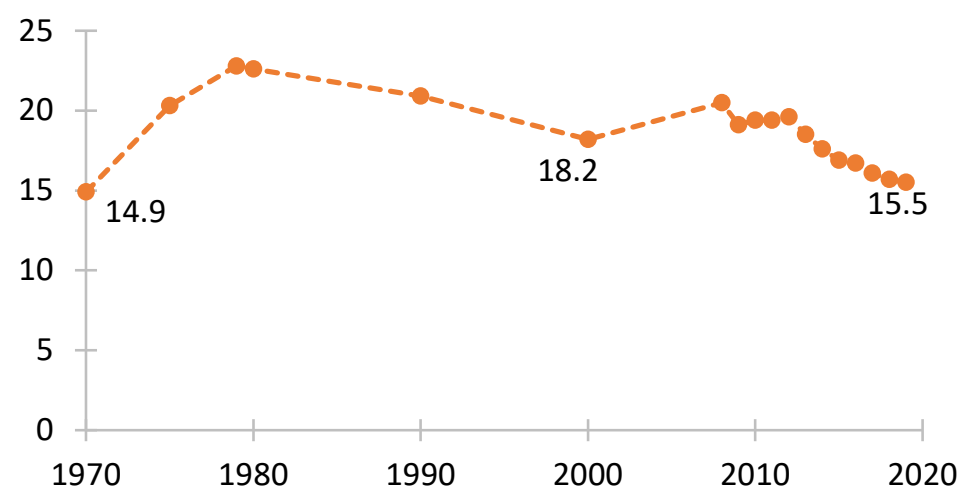

Sources: NCFMR analyses of 1970-2000, National Center for Health Statistics; 2008-2019, U.S. Census Bureau, American Community Survey, $1-y r$ est.

\section{Five Highest and Lowest Divorce Rates, 2019}

- In 2019, New Mexico held the top ranking for the highest divorce rate, with nearly 23 divorces per 1,000 married women.

- Arkansas held the highest divorce rate in 2018, with a rate of 26 divorces per 1,000 married women (FP-19-23). In 2019, it had the second highest rate at 21.5 per 1,000 married women.

- Maine had the lowest divorce rate in 2019, with around 9.6 marriages per 1,000 ending in divorce.

- North Dakota held the lowest divorce rate in 2018, with a rate of 8.7 divorces per 1,000 married women (FP-19-23). In 2019, it was at the top of the third quartile at 16 per 1,000 married women.

${ }^{2} \mathrm{MOE}=$ Margin of Error. The MOE is a measure of sampling error and expresses the maximum range in which the rate is expected to differ from the actual proportion. The MOE is calculated for the derived estimates at the $90 \%$ confidence level.

Figure 2. Women's Highest and Lowest Divorce Rates

\begin{tabular}{|c|c|c|}
\hline Rank \& State & Divorce Rate & $\mathrm{MOE}^{2}$ \\
\hline 1. New Mexico & 22.96 & $+/-\quad 6.36$ \\
\hline 2. Arkansas & 21.49 & $+/-\quad 3.49$ \\
\hline 3. Nevada & 20.97 & $+/-\quad 3.55$ \\
\hline 4. Oklahoma & 20.50 & $+/-2.53$ \\
\hline 5. Kentucky & 19.83 & $+/-\quad 2.13$ \\
\hline USA & 15.49 & $+/-\quad 0.3$ \\
\hline 46. New York & 12.55 & $+/-\quad 1.35$ \\
\hline 47. Wisconsin & 12.50 & $+/-\quad 1.04$ \\
\hline 48. Rhode Island & 11.95 & $+/-\quad 1.88$ \\
\hline 49. New Jersey & 10.89 & $+/-\quad 3.17$ \\
\hline 50. North Dakota & 9.58 & $+/-\quad 2.48$ \\
\hline
\end{tabular}

Source: NCFMR analyses of U.S. Census Bureau, American

Community Survey, 2019 1-yr est.

\section{Data Sources:}

Clarke. S. C. (1995). Advanced report of final marriage statistics, 1989 and 1990. Monthly Vital Statistics Report, 42(12). National Center for Health Statistics. https://www.cdc.gov/nchs/data/mvsr/supp/mv43_12s.pdf

National Center for Health Statistics (1974). Summary report final marriage statistics, 1970. Monthly Vital Statistics Report, 23(2), Supp. 1. U.S. Department of Health, Education, and Welfare. https://www.cdc.gov/nchs/data/mvsr/supp/mv23_02s1acc.pdf

National Center for Health Statistics (1977). Advance report of final divorce statistics, 1975. Monthly Vital Statistics Report, 26(2), Supp. 2. U.S. Department of Health, Education, and Welfare. https://www.cdc.gov/nchs/data/mvsr/supp/mv26_02s2acc.pdf

National Center for Health Statistics (1983). Advance report of final marriage statistics, 1980. Monthly Vital Statistics Report, 32(5), Supp. U.S. Department of Health and Human Services. https://www.cdc.gov/nchs/data/mvsr/supp/mv32_05s.pdf

National Center for Health Statistics (2001). Births, marriages, divorces, and deaths: Provisional data for January-December 2000. National Vital Statistics Report, 49(6), Associated Table 3. Department of Health \& Human Services, Center for Disease Control and Prevention. https://www.cdc.gov/nchs/data/nvsr/nvsr49/nvsr49_06.pdf

U.S. Census Bureau (2019). American Community Survey, 2019 1-Year Estimates [Table B12001]. https://data.census.gov/cedsci/table?q=B12001\&lastDisplayedRow=18\&table=B12001\&tid=ACSDT1Y2018.B12001

U.S. Census Bureau (2019). American Community Survey, 2019 1-Year Estimates [Table B12503].

https://data.census.gov/cedsci/table?q=B12503\&hidePreview=false\&table=B12503\&tid=ACSDT1Y2018.B12503\&lastDisplayedRow=10 


\section{State Rankings and Geographic Variation in Divorce Rates, 2019}

Figure 3. State Variation in the Adjusted Divorce Rate per 1,000 Married Women Aged 15+ by Quartile, 2019

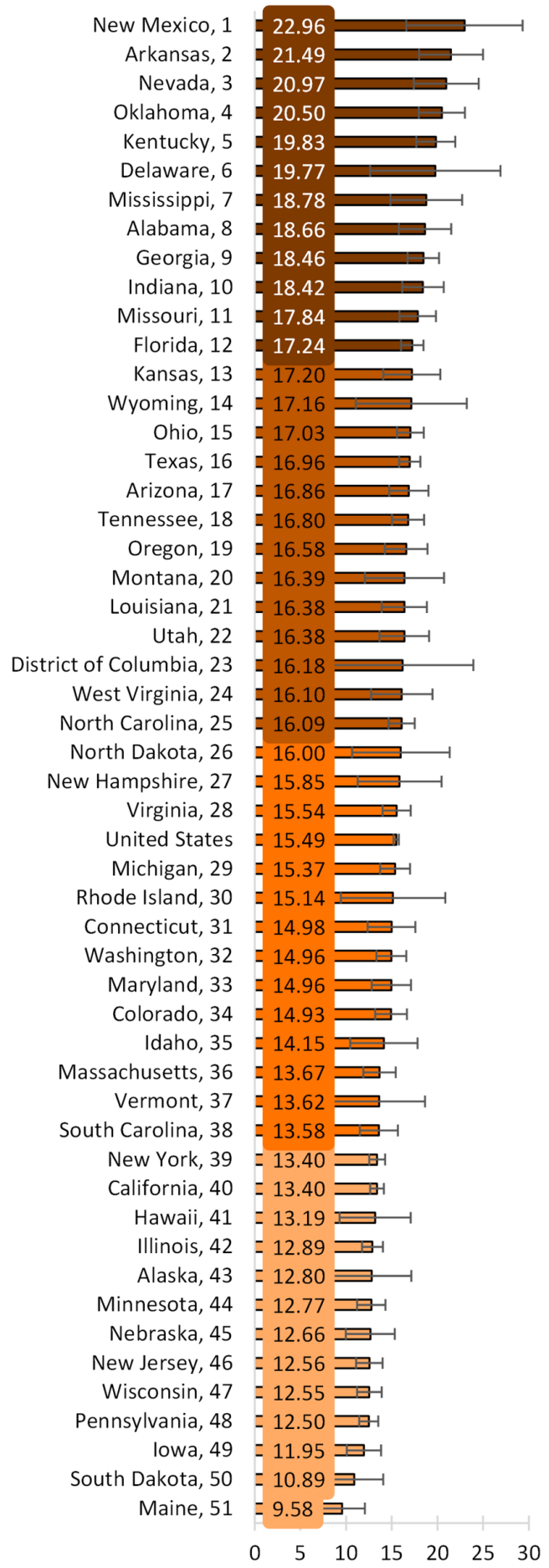

Source: NCFMR analyses of U.S. Census Bureau, American Community Survey, 2019 1-yr est.
- The 12 states with the highest divorce rates (making up the first quartile) had rates of at least 17.24 divorces per 1,000 married women in 2019.

- The 13 states that experienced the lowest divorce rates (making up the fourth quartile) had fewer than 13.4 divorces per 1,000 married women in 2019.

Figure 4. Geographic Variation of Women's Adjusted Divorce Rate Among States, 2019

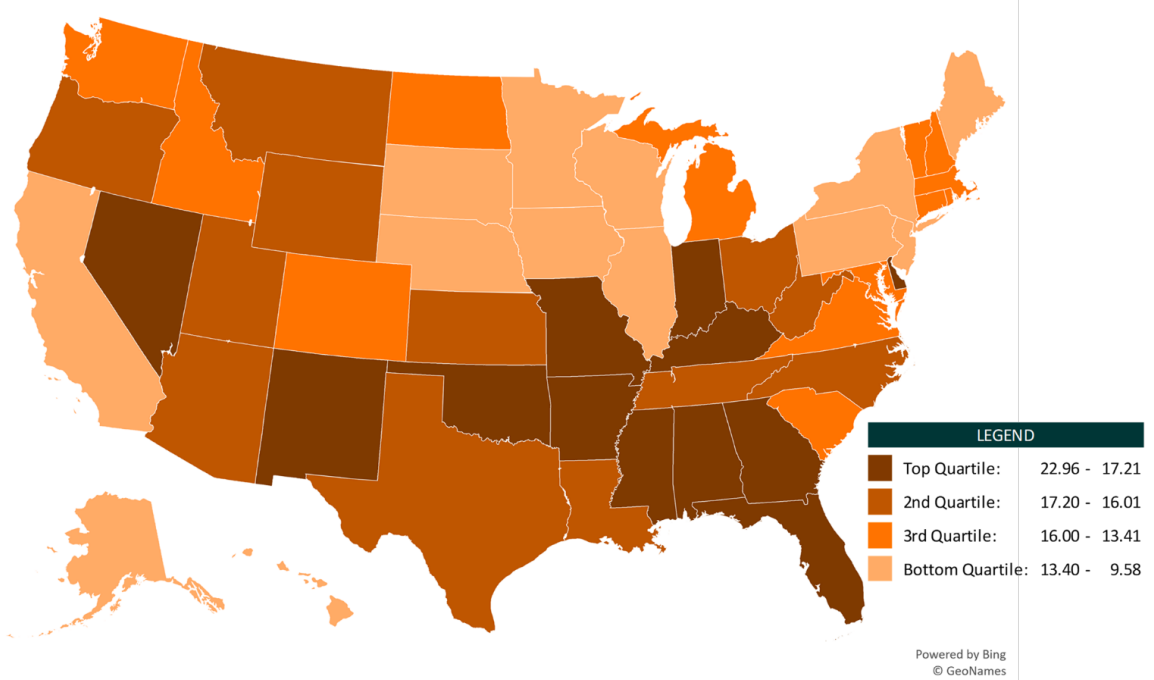

Source: NCFMR analyses of U.S. Census Bureau, American Community Survey, 2019 1-yr est.

- Most states in the South had high divorce rates (in the first or second quartiles).

- Exceptions included Virginia, Maryland, and South Carolina, all of which were in the third quartile.

- States with the lowest divorce rates (in the third or fourth quartiles) were mostly located in the Midwest and Northeast regions of the U.S.

- Exceptions included Ohio, Kansas, Missouri, and Indiana, which were in the first two quartiles of divorce rates.

- States in the Western region of the country exhibited divorce rates in all four quartiles, with the largest share found in the second quartile.

References:

Allred, C. (2019). Divorce rate in the U.S.: Geographic variation, 2018. Family Profiles, FP-19-23. Bowling Green, $\mathrm{OH}$ : National Center for Family \& Marriage Research. https://doi.org/10.25035/ncfmr/fp-18-23

Hemez, P. (2017). Divorce rate in the U.S.: Geographic variation, 2016. Family Profiles, FP-17-24. Bowling Green, $\mathrm{OH}$ : National Center for Family \& Marriage Research. https://doi.org/10.25035/ncfmr/fp-17-24

Payne, K. K. (2018). Charting marriage and divorce in the U.S.: The adjusted divorce rate. Bowling Green, OH: National Center for Family \& Marriage Research. https://doi.org/10.25035/ncfmr/adr-2008-2017

Schweizer, V. (2018). Divorce rate in the U.S.: Geographic variation, 2017. Family Profiles, FP-1821. Bowling Green, $\mathrm{OH}$ : National Center for Family \& Marriage Research. https://doi.org/10.25035/ncfmr/fp-18-21

\section{Suggested Citation:}

Reynolds, L. (2020). Divorce rate in the U.S.: Geographic variation, 2019. Family Profiles, FP-20-25. Bowling Green, OH: National Center for Family \& Marriage Research. https://doi.org/10.25035/ncfmr/fp-20-25 